\title{
Sıvı Vanadyumun Kristalizasyon Sürecine Soğutma Oranı Etkisinin Moleküler Dinamik Benzetim Metodu ile İncelenmesi
}

\author{
Murat ÇELTEK ${ }^{1 *} \mathbb{0}$, Vildan GÜDER ${ }^{2}$ \\ ${ }^{1}$ Trakya Üniversitesi, Eğitim Fakültesi, Matematik ve Fen Bilimleri Eğitimi Bölümü, 22030, Edirne, Türkiye \\ ${ }^{2}$ Trakya Üniversitesi, Fen Fakültesi, Fizik Bölümü, 22030, Edirne, Türkiye
}

Geliş / Received: 12/04/2020, Kabul / Accepted: 30/08/2020

\begin{abstract}
$\ddot{O} z$
Isıtma ve soğutma süreçlerinde vanadyumun mikro yapısal değişimleri ve soğutma hızının kristalizasyon süreci üzerine etkileri gömülü atom metodu kullanılarak moleküler dinamik benzetim yöntemi ile araştırıldı. Soğutma oranın etkisi sekiz farklı soğutma oranı $(\mathrm{Q}=0.05-10 \mathrm{~K} / \mathrm{ps})$ kullanılarak araştırıldı ve sonuçlar çiftler dağılım fonksiyonu, Honeycutt-Andersen ve Voronoi mozaikleme analiz yöntemleri kullanılarak analiz edildi ve ayrıntılı bir şekilde tartışıldı. Erime noktası civarında hesaplanan çiftler dağılım fonksiyonu ve yapı faktörünün deneysel sonuçlarla tutarlı olduğu gözlenmiştir. Daha yavaş soğutma oranları için kristalizasyon sıcaklığından başlayarak ideal bcc kristal yapıyı temsil eden 1441 ve 1661 bağlı çiftlerinin ve $<0,6,0,8>$ kümelerinin ani ve bir o kadar keskin bir artış1 izlenmiştir. Daha düşük sıcaklıklarda söz konusu bağlı çiftlerin ve kümelerin dağılımlarının ısıtma sürecinde elde edilen sonuçlarla neredeyse üst üste olduğu gözlenmiştir. Bu sonuçlar yavaş soğutma oranları için sistemin sıvı yapıdan ideal bcc kristal yapıya geçiş yaptığının açık delilidir. Sistem daha hızlı soğutulduğunda, bcc kümelerin yanı sıra başka kristal kümelerin de oluştuğu gözlenmiştir.
\end{abstract}

Anahtar Kelimeler: Kristalizasyon, Gömülü Atom Metodu, Çiftler Analiz, Voronoi Mozaikleme

Investigation of Cooling Rate Effect of Liquid Vanadium on the Crystallization Process with Molecular Dynamic Simulation Method

\begin{abstract}
The microstructural changes of vanadium in the heating and cooling processes and the effects of the cooling rate on the crystallization process were investigated by the molecular dynamics simulations method using the embedded atom method. The effect of the cooling rate was investigated using eight different cooling rates $(\mathrm{Q}=0.05-10 \mathrm{~K} / \mathrm{ps})$, and the results were analyzed and discussed in detail using the pair distribution function, Honeycutt-Andersen and Voronoi tessellation analysis methods. It was observed that the pair distribution function and structure factor calculated around the melting point were consistent with the experimental results. Starting from the crystallization temperature point for slower cooling rates, there was a sudden and sharp increase in the number of 1441 and 1661 bounded pairs and <0,6,0,8> clusters representing the ideal bcc crystal structure. It was observed that the distributions of these bonded pairs and clusters at lower temperatures were nearly overlapping with the results obtained during the heating process. These results are clear evidence that the system transition from liquid to ideal bcc crystal structure for slow cooling rates. When the system was cooled faster, it was observed that it formed in other crystal clusters besides bcc clusters.
\end{abstract}

Keywords: Crystallization, Embedded Atom Method, Pair Analysis, Voronoi Tessellation

\section{Giriş}

*Sorumlu yazar: mceltek@ trakya.edu.tr
Amorf ve polikristal katılar gibi birçok malzeme genellikle sıvı malzeme üzerine 
katılaştırma işlemi uygulanarak hazırlanır. Cam veya amorf fazın dondurulmuş sıvı olduğu düşünülür ve bu, sıvı haldeki çeşitli atom kümelerinin, soğutma koşulları altında kristal oluşturmak için yeterli zamana sahip olmadıkları anlamına gelir (Celik, 2012; Schuh vd., 2007). Bu durumda numunenin soğutulması için verilen süre veya kullanılacak olan soğutma hızının belirlenmesi büyük önem arz etmektedir. Metalik eriyiklerin katılaşması sırasında mikro yapılarında ne tür değişmelerin olduğunun anlaşılabilmesi hem yoğun madde hem de malzeme biliminde büyük öneme sahiptir. Bu süreci tam olarak anlamak için, sıvı yapının doğru bir açıklaması ile başlanmalı ve sıcaklığın fonksiyonu olarak kristalleşme süreci takip edilmelidir. Bir sıvının moleküler dinamik (MD) benzetimlerinde katı oluşturmak üzere kristalleştirilmesi ilk olarak Alder ve Wainwright (1957) tarafindan katı küre akışkanı ve Mandell ve arkadaşları Mandell vd., (1977) tarafından Lennard-Jones akışkanı için gözlenmiş ve sonrasında diğer sıvıların kristalleşme süreci üzerine birçok MD benzetim çalışması gerçekleştirilmiştir. Son y1llarda, metalik eriyiklersin atomik yapısı ve kristalizasyonu ile sıvı - katı ara yüzünün anlaşılmasında hem deneysel Egry ve Holland-Moritz (2011); Itami vd. (2003); Kelton vd. (2003); Kim vd. (2005); Lou vd. (2013); Mauro vd. (2011); Schenk vd., (2002); Shuleshova vd. (2012) hem de teorik olarak Ashkenazy ve Averback (2010); Debela vd. (2014); Ganesh ve Widom (2006); Hoyt vd. (2006); Jakse ve Pasturel (2003); Jakse ve Pasturel (2004); Thakor vd. (2011); Wu vd. (2011); Zhang ve Huang (2006) önemli ilerlemeler kaydedilmiştir. Fakat bütün bu ilerlemelere rağmen atomik ölçekte kristal çekirdeklenmesi ve büyümesi konusundaki bilgimiz oldukça sınırlıdır. Çekirdeklenme olayı, kısa bağ uzunlukları ve zaman ölçekleri gibi nedenlerden dolayı deneysel incelenmesi zor bir süreçtir. $\mathrm{Bu}$ zorluğun üstesinden gelebilmek ve kristalizasyonun temel sürecini araştırabilmek için kolloidal sistemler kullanılmıştır (Schöpe vd., 2006). Çalışmamızın temel eksenindeki vanadyumun en yaygın olarak kullanıldığ alan çelik endüstrisidir. Buna ek olarak uzay araçları, uçak sanayi ve otomobil endüstrisi gibi birçok alanda da titanyumlu alaşımlarla birlikte vanadyum kullanılmaktadır. Diğer yandan kolayca radyoaktif hale gelmeyen, yüksek sıcaklıklarda iyi mukavemet gösteren, yüksek termal stres faktörüne, düşük termal genleşme ve elastik modülüne sahip vanadyum bazlı alaşımlar, düşük aktivasyonu ve yüksek radyasyon direncinden dolayı nükleer füzyon cihazlarında yapısal malzeme olarak kullanım için önemli avantajlara sahiptir Morishita vd. (1995) ve gelecekte füzyon reaktörlerinde kullanılmak üzere aday yapısal malzemeler arasında görülmektedirler (Chung vd., 1996). Bu önemli özellikler saf vanadyuma ve alaşımlarına olan ilgiyi hem deneysel hem de teorik olarak artırmıştır (Zinkle vd., 1998). Vanadyum ve alaşımlarının yapısal Ori vd. (2011), elektronik Silvestrelli ve Ambrosetti (2019), mekanik ve termodinamik özellikleri Sorkin vd. (2003a ve b) yanı sira kristalizasyon süreçleri Debela vd. (2014) ile ilgili farklı çalışmalar yapılmış olsa da soğutma süreci boyunca saf vanadyumun yapısal gelişimi ve kristalizasyonu süreci ile ilgili halen anlaşılamayan birçok nokta vardır. Bu boşluk bizi birçok eşsiz özelliğe ve geniş bir kullanım alanına sahip vanadyumun soğutma süreci ve kristalizasyonu üzerine araştırma yapmak için motive etmiştir. Mevcut çalışmamızda 1sıtma ve soğutma süreçlerinde vanadyum atomları arasındaki atomik etkileşmeler, birçok metalik sistem için başarılı sonuçlar verdiği rapor edilen Celtek ve Sengul (2018b); Çeltek ve Şengül (2019); Celtek vd. (2017); Celtek 
(2019); Sengul vd. (2020), gömülü atom metodu (GAM) kullanılarak MD benzetimleri ile gerçekleştirilmiştir. Her iki süreçte sistemin atomik yapısında meydana gelen değişimleri tartışmak için çiftler dağılım fonksiyonu (ÇDF), çiftler analiz (ÇA) ve Voronoi mozaikleme (VM) analiz yöntemlerinden elde edilen sonuçlar kullanılmıştır. Çalışmanın ikinci bölümünde GAM potansiyeli, ÇDF, ÇA ve VM metodu hakkında bilgiler sunulmuş olup, üçüncü bölümde veriler ve analiz sonuçları alan yazımdaki uygun deneysel ve diğer MD benzetim sonuçları ile karşılaştırmalı ve ayrıntılı bir şekilde tartışılmıştır. Son bölümde ise çalışmanın kısa bir tartışma ve sonucu sunulmuştur.

\section{Materyal ve Metot}

$\mathrm{Bu}$ bölümde, ısıtma ve soğutma süreçlerinde izlenilen MD benzetim prosedürü ve sistemdeki atomik etkileşmeleri tanımlamak için kullanılan GAM potansiyeli hakkında bilgi verilmiştir. Ek olarak MD benzetimden elde edilen verilerin analizi için kullanılan, ÇDF, ÇA Honeycutt ve Andersen (1987) ve VM Voronoi (1908) analiz metodu ile ilgili kısa bilgiler sunulmuştur.

\subsection{Moleküler prosedürü}

Vanadyumun 1sitma ve soğutma süreçlerinin MD benzetimleri, Todorov ve arkadaşları tarafindan Daresbury Laboratuvarında geliştirilen genel amaçlı paralel MD benzetim paketi olan DLPOLY_4.03 Todorov vd. (2006) açık kaynak kodu kullanılarak gerçekleştirilmiştir. Diğer yandan düşük sicaklıklarda vanadyumun elastik sabitlerini hesaplayabilmek için ise yine açık kaynak olarak sunulan Büyük Ölçekli AtomikMoleküler Kütle Paralel Simülatörü olan LAMMPS kodundan yararlanılmıştır
(Plimpton, 1995). MD benzetim hücresindeki etkileşmeleri açıklayabilmek için Olsson Olsson (2009) tarafindan parametrize edilen, daha sonra MD benzetimlerde kullanılmak üzere LAMMPS kodu için çoğaltılan ve "https://www.ctcms.nist.gov/potentials/Down load/2009--Olsson-P-A-T--

V/2/V_Olsson_CMS2009.eam.alloy" linki ile paylaşılan GAM potansiyel verisi kullanılmıştır. Başlangıçta sistemin yapısı vanadyum için en kararlı yapı olan cisim merkezli kübik (bcc) yapıda kurulmuştur (İlgili analiz sonuçları Şekil 1'de gösterilmiş ve tartışılmıştır). Birim hücresinde 2 atom barındıran bcc kristal yapıya sahip hücreye her üç yönde periyodik sınır şartları uygulanmış ve MD benzetim hücresindeki toplam atom say1s1 $2 \times(20 \times 20 \times 20)=16000$ olacak şekilde belirlenmiştir. Newton hareket denklemlerini çözebilmek için Verlet algoritmasının hız formu kullanılmıștır. Bütün MD benzetimlerde sıcaklığı ve basıncı kontrol altında tutabilmek için Berendsen termostat ve barostatı kullanılmıştır. Başlangıç olarak sistem üzerindeki stresi almak için 5,000,000 MD adımı ile sistem $300 \mathrm{~K}$ sıcaklık değerinde dengeye getirildi ve daha sonra ayn MD adımı ile sistem $0 \mathrm{~K}$ sıcaklığa soğutuldu. Stresi alınan sistem, $0 \mathrm{~K}$ den başlayarak $50 \mathrm{~K}$ artışlarla vanadyumun erime noktasının $\left(T_{e}=\right.$ 2183 K Haynes (2015)) çok üzerinde bir sicaklık olan 3000 K'e kadar izotermalizobarik (NPT) topluluğu kullanılarak ve zaman adımı 1 fs seçilerek 1sıtılmıştır. Bu işleme karşılık gelen MD benzetim 1sıtma oran1 $\mathrm{Q}=0.5 \mathrm{~K} / \mathrm{ps}$ 'dir. Son olarak 3000 $\mathrm{K}$ 'deki siv1 sistem $\mathrm{Q}_{1}=0.05, \mathrm{Q}_{2}=0.1, \mathrm{Q}_{3}=0.5$, $\mathrm{Q}_{4}=1, \mathrm{Q}_{5}=3, \mathrm{Q}_{6}=5, \mathrm{Q}_{7}=7$ ve $\mathrm{Q}_{8}=10 \mathrm{~K} / \mathrm{ps}$ soğutma oranları ile $50 \mathrm{~K}$ sicaklık adımı ile $300 \mathrm{~K}$ 'e kadar adım adım soğutulmuştur. 


\subsection{Gömülü atom metot potansiyeli}

Çalışmamızda vanadyumun atomik yapısında meydana gelen değişiklikleri, erime ve kristalizasyon süreçlerini doğru bir şekilde açıklayabilmek için GAM potansiyelini kullandık. GAM yaklaşımına göre toplam enerji, sistemdeki bir atomun elektrostatik itici etkileşmelerinin toplamı ile bu atomun koordinatlarındaki elektronik yük yoğunluğundan kaynaklanan gömme enerjisi terimlerinin toplamı olarak ifade edilir. Mevcut tanıma göre $N$-atomlu bir sistemin toplam enerjisi Daw ve Baskes (1984),

$$
E=\frac{1}{2} \sum_{i, j, i \neq j} \phi_{i j}\left(r_{i j}\right)+\sum_{i} F_{i}\left(\rho_{i}\right)
$$

şeklinde verilir. Burada, $\phi_{i j}\left(r_{i j}\right)$ aralarında $r_{i j}$ mesafesi bulunan $i$ ve $j$ atomları arasındaki çiftler etkileşim potansiyelidir. $F_{i}\left(\rho_{i}\right)$ ise bir $i$ atomunu $\rho i$ elektronik yük yoğunluğunun bulunduğu bir konuma yerleştirmek için gereken enerjidir ve gömme enerjisi olarak ifade edilir. $\rho_{i}$ ifadesi $i$ atomunu çevreleyen diğer komşu atomların atomik yük yoğunluklarının toplamı olup

$$
\rho_{i}=\sum_{j, j \neq i} f_{j}\left(r_{i j}\right)
$$

şeklinde yazılır. Son ifadede $f_{j}\left(r_{i j}\right)$ atomik yük yoğunluk fonksiyonudur.

\section{3. Çiftler dağılım fonksiyonu}

ÇDF analizi MD benzetim çalışmalarında bir sistemin 1sitma ve soğutma süreçlerinin gelişimini incelemek için en çok kullanılan yapısal yöntemlerin başında gelir. ÇDF (veya $g(r))$ en basit şekliyle belirli bir atomdan " $r$ " mesafe uzaklıkta başka bir atomun bulunma olasılığı olarak tanımlanır. $\mathrm{Bu}$ tanıma göre $g(r)^{\prime}$ nin formu Celtek vd. (2020);

$$
g(r)=\frac{V}{N^{2}}\left\langle\sum_{i=1}^{n} \frac{n(r)}{4 \pi r^{2} \Delta r}\right\rangle
$$

olarak verilir. Burada $N, V$ ve $n(r)$ sirasıyla benzetim kutusundaki atom sayısını, benzetim kutusunun hacmini ve $r$ ile $r+\Delta r$ aralığında bulunan parçacıkların sayısını göstermektedir (Çeltek vd., 2019).

\section{4. Çitfler ve Voronoi Mozaikleme Analiz Yöntemleri}

Çoğu zaman 1sıtma veya soğutma süreçlerine bağlı olarak çalışılan numunenin mikro yapısında ne tür değişmelerin olduğunu bilmek önem arz eder. Yukarı bahsedilen $g(r)$ gibi analiz yöntemleri bu durumlarda yetersiz kalabilir. Sistemin mikro yapısındaki değişmeleri daha ayrıntılı ve güvenilir bir şekilde analiz edebilmek için çoğunlukla Honeycutt-Andersen (HA) Honeycutt ve Andersen (1987) çiftler analiz ve VM Voronoi (1908) analiz yöntemleri kullanılmaktadır. Bu yöntemlerden HA indeksi ijkl gibi 4 tamsayıdan oluşur. Eğer atom çifti arasındaki mesafe $r$ 'den azsa (burada $r, g(r)$ 'nin ilk minimumunun konumuna karşıllık gelen değerdir), atom çiftleri kök çiftine bağlandığında ilk tam sayı 1 olur, aksi takdirde $i 2$ değerini alır. $j$ tamsayısı, kök çift için ortak komşu sayısını temsil eder. $k$ tamsayısı, paylaşılan komşular arasındaki bağ sayısını gösterir. Son olarak, ilk üç endeks aynı fakat geometrileri farklı ise bu yapıları birbirinden ayır etmek için $l$ tamsayısı kullanılır. Örnek olarak 1421 ve 1422 yapıları verilebilir. Mevcut tanımlara göre, 1551 endeksi, mükemmel ikozahedra yerel düzeni karakterize ederken, 1541 ve 1431 endeksleri, zorlanmış ikozahedra düzeni karakterize eder. 1421 endeksi fcc düzeni ve $1421+1422$ endeksi hcp düzeni temsil ederken, 1661 ve 1441 endeksleri bcc düzeni temsil eder (Honeycutt ve Andersen, 1987). VM analiz yöntemi ise bir atomu çevreleyen diğer komşu 
atomlar tarafindan oluşturulan atomik kümelerin (veya Voroi polihedra (VP)) karakterleri hakkında daha ayrıntılı bilgiler verir. Sistemde ortaya çıkacak olan VP'ler birbirlerinden dört Voronoi indeksi $<n_{3}, n_{4}, n_{5}$, $n_{6}>$ ile ayırt edilebilirler. Burada $n i$, VP'deki $i$-kenarlı yüzlerin sayısını temsil eder. Örneğin, $\quad<0,0,12,0>\quad$ kümesi, ideal ikosahedron anlamına gelir ve 12 koordineli 12 tane beş-katlı bağ olduğunu belirtir, $<0,6,0,8>$ VP'si ise ideal bcc kümeleri temsil eder ve 14 koordineli 6 tane dört-katlı ve 8 tane alt1-katlı bağ olduğunu belirtir. $\mathrm{Bu}$ yöntem HA analizine göre merkezi atomun çevresindeki komşu atomların oluşturduğu kümelerin geometrilerini daha açık bir şekilde tanımlamaktadır (Sengul ve Celtek, 2018).

\section{Bulgular}

Mevcut çalışmamızda mono atomik vanadyumun mikro yapısının 1sitma ve soğutma süreçlerinde gelişimi ile soğutma oranının kristalizasyon sürecine etkileri GAM potansiyeli kullanılarak MD benzetim yöntemi ile araştırıldı. MD benzetim yöntemlerinin güvenilir sonuçlar verebilmesinin ilk ve en önemli koşul, sistemdeki atomik etkileşmeleri en doğru ve hızlı bir şekilde tanımlayan transfer edilebilir bir atomlar arası çiftler potansiyelden geçer. Diğer bir değişle, seçilen potansiyelin hem düşük hem de yüksek sıcaklıklarda sistemin fiziksel özelliklerini doğru ve güvenilir bir şekilde açıklaması beklenir. GAM potansiyelinin, vanadyum elementi için geçerliliğini test etmek adına en yaygın bilinen beş kristal yapıda (basit kübik (sc), yüzey merkezli kübik (fcc), cisim merkezli kübik (bcc), altıgen sıkı paket yapı (hcp) ve elmas yapı birim hücreler oluşturuldu. $0 \mathrm{~K}$ sıcaklıkta ve $0 \mathrm{GPa}$ basınç altında her bir yapının örgü sabiti $0.01 \quad \AA$ adımlar ile değiştirildi ve her örgüye karşılık gelen enerji değerleri Şekil 1'de karşılaştırılarak verildi. Beklendiği gibi vanadyum için GAM potansiyeli, deneysel ve ilk prensip yöntemlerinde olduğu gibi en kararlı yapının bcc yap1 olduğunu ortaya koymaktadır. Buna ek olarak GAM potansiyeli bcc yapının enerjisinden daha büyük olan hcp ve fcc kristal yapıların enerjilerinin birbirine çok yakın olduğunu ve daha sonra bunları sc ve elmas yapıların takip ettiğini ortaya koymaktadır.

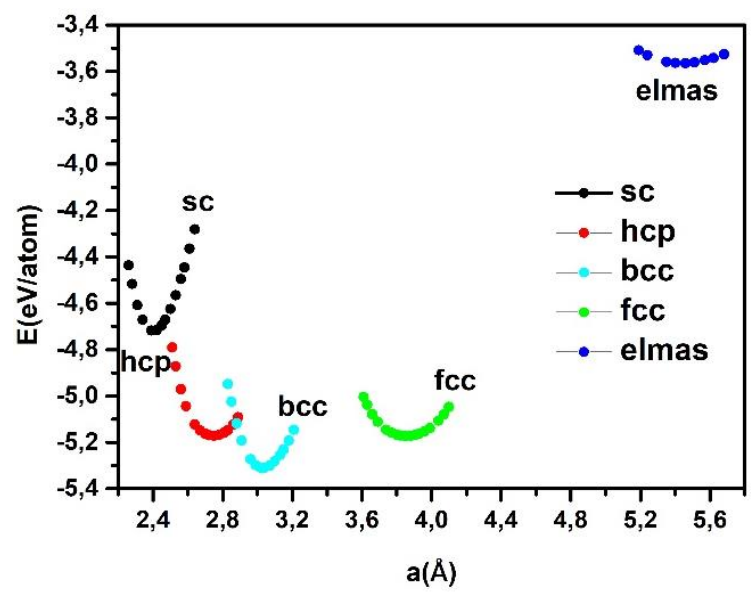

Şekil 1. Vanadyum için örgü sabitinin bir fonksiyonu olarak seçilen kristal yapılardaki atom başına enerji değişimi.

En kararlı yap1 olan bcc kristal yapı için $0 \mathrm{~K}$ de hesaplanan bazı fiziksel özellikler daha önce rapor edilen deneysel ve diğer teorik yöntemlerle elde edilen değerlerle karşılaştırmalı olarak Tablo 1'de verilmiştir. MD benzetim yöntemiyle hesaplanan ve Tablo 1'de verilen örgü sabiti, bağlanma enerjisi, elastik sabitler, Bulk modülü, Shear modülü ve Poisson oranı gibi fiziksel değerler literatürdeki ilgili deneysel ve diğer teorik sonuçlar ile birbirine oldukça yakındır. $\mathrm{Bu}$ sonuçlar sistemdeki vanadyum atomları arasındaki etkileşmeleri tanımlamak için seçilen GAM potansiyelinin düşük sıcaklıklarda katı sistemin fiziksel özellikleri doğru ve güvenilir bir şekilde açıklayabildiğini göstermektedir. Isıtma ve soğutma süreçleri için elde edilen atom başına 
toplam enerjinin sıcaklığa bağlı değişimlerini gösteren E-T eğrileri Şekil 2'de karşılaştırmalı olarak verilmiştir.

Tablo 1. bcc kristal vanadyum için GAM potansiyeli kullanılarak hesaplanan bazı fiziksel özellikler.

\begin{tabular}{lll}
\hline Örgü özellikleri & $\begin{array}{l}\text { Bu } \\
\text { çalışma }\end{array}$ & Deneysel \\
\hline $\mathrm{a}(\AA)$ & 3.029 & $3.030^{\mathrm{a}}$ \\
$\mathrm{E}(\mathrm{eV} /$ atom $)$ & -5.31 & $-5.31^{\mathrm{a}}$ \\
Elastik sabitler (GPa) & \\
\hline $\mathrm{C}_{11}$ & 232.399 & $235.89^{\mathrm{b}}$ \\
& & $231.65^{\mathrm{c}}$ \\
$\mathrm{C}_{12}$ & 119.345 & $120.76^{\mathrm{b}}$ \\
& & $120.30^{\mathrm{c}}$ \\
$\mathrm{C}_{44}$ & 45.965 & $46.55^{\mathrm{b}}$ \\
& & $44.03^{\mathrm{c}}$ \\
Bulk Modülü & 157.029 & $157.41^{\mathrm{c}}$ \\
(GPa) & & \\
Shear Modülü & 56.527 & $57.56^{\mathrm{b}}$ \\
(GPa) & & \\
Poisson Oranı & 0.33 & $0.36^{\mathrm{b}}$ \\
& &
\end{tabular}

aittel (1986); ${ }^{\mathrm{b}}$ Greiner vd. (1979); ${ }^{\mathrm{c} B o l e f} \mathrm{vd}$. (1971).

Isıtma sürecinde E- $T$ eğrisi $300 \mathrm{~K}$ ile $2300 \mathrm{~K}$ aralığında sıcaklığa bağlı olarak neredeyse lineer olarak artarken, $2300 \mathrm{~K}$ ile $2350 \mathrm{~K}$ arasında ani bir değişim meydana gelmiştir. $\mathrm{Bu}$ ani değişim katı kristal vanadyumun faz değiştirerek sıvı yapıya geçiş yaptığının açık bir göstergesidir. Değişimin başladığı sıcaklık noktası erime sicaklığ $\quad\left(T_{e}=2300 \pm 25 \quad \mathrm{~K}\right)$ olarak adlandırılırken, ani artışın son bulduğu nokta ise sivı olma $\left(T_{s}=2350 \pm 25 \mathrm{~K}\right)$ sicaklığ olarak adlandirılır. MD benzetimden belirlenen erime sıcaklığı deneysel erime sicaklığından $\left(T_{e}=2183 \mathrm{~K}\right.$ Haynes (2015)) $\sim 117 \mathrm{~K}$ daha yüksektir ve sapma miktarı \% 5.36 kadardır. MD benzetim ve deneysel şartlar arasındaki farklılıklar göz önünde tutulduğunda sonuçlar aradaki fark kabul edilebilir ölçüdedir. $T_{s}$ noktasından sonra E- $T$ eğrisi devam eden sıcaklık artışıyla birlikte 3000 K'e kadar neredeyse lineer bir artış göstermektedir ki bu da sistemin erime sonrası halen sıvı yapıda olduğunu göstermektedir. Sistem $\mathrm{Q}_{1}=0.05, \mathrm{Q}_{2}=0.1, \mathrm{Q}_{3}=0.5, \mathrm{Q}_{4}=1, \mathrm{Q}_{5}=3$, $\mathrm{Q}_{6}=5, \mathrm{Q}_{7}=7$ ve $\mathrm{Q}_{8}=10 \mathrm{~K} / \mathrm{ps}$ olarak seçilen sekiz farklı soğutma oranı kullanılarak soğutulduğunda $T_{s}$ sicaklığının üzerindeki sıcaklıklarda 1sıtma ve soğutma süreçlerine ait E- $T$ eğrileri neredeyse üst üstedir. Bu davranış bütün sistemler için yüksek sıcaklıklarda atomların yeterince hızlı hareket edebildiğini gösterir. S1caklık $T_{s}$ ' in altına düştügüünde tüm soğutma oranları için E- $T$ eğrileri daha düşük sicaklıklara (2350-1500 K arası) doğru üst üste lineer düşüşünü devam ettirmekte ve $\sim 1500 \mathrm{~K}$ 'den itibaren soğutma oranına göre farklılıklar oluşmaktadır. E- $T$ eğrilerinde ilk keskin kırılma en yavaş soğutma oranı olan $\mathrm{Q}_{1}=0.05 \mathrm{~K} / \mathrm{ps}$ için görülmektedir. Bu değişim 1sitma sürecinde E- $T$ eğrisinde olduğu gibi çok ani ve keskindir. $1500-1450 \mathrm{~K}$ arasında meydana gelen ani düşüş soğutma sürecinde sistemin sıv1 yapıdan kristal benzeri bir yapıya geçiş yaptığını göstermektedir ve bu soğutma oranı için kristalizasyon sıcaklığ $T_{k}=1450 \pm 25$ $\mathrm{K}$ olarak belirlenmiştir. Bu sonuçlara bakarak sistemin hangi kristal yapaya geçiş yaptığını kesin olarak söylemek zordur. Fakat 1450-300 $\mathrm{K}$ arasındaki 1sıtma ve soğutma E-T eğrilerinin neredeyse üst üste olması sistemin kristal yapıs1 hakkında önemli bir ipucu vermektedir. Isıtma sürecine ideal bcc kristal yap1 ile başlandığ 1 için, $\mathrm{Q}_{1}=0.05 \mathrm{~K} / \mathrm{ps}$ ile soğutulan sistemin $1450 \mathrm{~K}$ civarından siv1 yapıdan bcc-kristal benzeri yapıya geçiş yaptığını söyleyebiliriz. Daha tutarlı bir karar vermek için sonraki bölümlerde farklı analiz yöntemleri kullanılarak elde edilen sonuçlar 
ayrıntılı olarak tartışılacaktır. Benzer davranış gösteren $\mathrm{Q}_{2}=0.1, \mathrm{Q}_{3}=0.5, \mathrm{Q}_{4}=1$ ve $\mathrm{Q}_{5}=3 \mathrm{~K} / \mathrm{ps}$ soğutma oranları için kristalizasyon sicaklıkları sirasıyla $T_{k}=1350,1300,1250$ ve $1100 \pm 25 \mathrm{~K}$ olarak belirlenmiştir. Bunlardan farklı olarak $\mathrm{Q}_{6}=5, \mathrm{Q}_{7}=7$ ve $\mathrm{Q}_{8}=10 \mathrm{~K} / \mathrm{ps} \mathrm{h}_{1} \mathrm{l}_{1}$ soğutma oranları için E- $T$ eğrilerindeki sıv1kristal benzeri geçişler daha geniş sıcaklık aralıklarına yayılmakta ve $\mathrm{Q}_{7}=7$ ile $\mathrm{Q}_{8}=10$ $\mathrm{K} / \mathrm{ps}$ için ise belirgin bir kırılma görülmemektedir. Bu sonuçlar hızlı soğutma oranları için daha geniş sıvı-katı geçiş sıcaklığı aralığında çok kristalli yapıların varlığına işaret eder. Diğer soğutma oranlarının aksine, $\mathrm{Q}_{7}=7$ ile $\mathrm{Q}_{8}=10 \mathrm{~K} / \mathrm{ps}$ için elde edilen enerji değerlerinin diğerlerinden daha yüksek ve eğrilerinin davranışının diğerlerinden farklı olması bu görüşü destekler niteliktedir. Ek olarak $\mathrm{Q}_{6}=5, \mathrm{Q}_{7}=7$ ve $\mathrm{Q}_{8}=10 \mathrm{~K} / \mathrm{ps}$ hızlı soğutma oranları için kristalizasyon sıcaklıkları sirasıyla 900, 750 ve $650 \pm 25 \mathrm{~K}$ olarak belirlenmiştir. Erime noktası ve kristalizasyon sicaklığı arasında kalan aşırı soğutulmuş bölge, soğutma oranındaki artışla beraber genişlemektedir. Diğer bir deyişle daha hızlı soğutulan sistemin aşırı soğutulmuş bölge aralığı yavaş soğutulan sisteme göre daha geniştir. Vanadyum için soğutma oranının logaritmasının bir fonksiyonu olarak belirlenen $T_{k}$ sicaklıkları Şekil 2'de verilmektedir. $\log (\mathrm{Q})$ ve $T_{k}$ arasında lineer bir değişim gözlenmemiştir. Sistem ne kadar hızlı soğutulursa o kadar küçük sıcaklıklara doğru sıvı-katı faz geçişi gerçekleşirken, sistemin soğutma hızı düştükçe kristalizasyon sıcaklığı da daha büyük sıcaklıklara doğru parabolik artmaktadır. $\mathrm{Bu}$ sonuç MD benzetim yöntemlerinde kullanılan benzetim adımı ile alakalıdır. Sonuçlarımız sistemin dengeye gelmesi için tanınan sürenin (MD benzetim adımının) artmasının sistemin sıv1-katı faz geçişini daha öne çektiğini göstermektedir. Buda numunenin soğutulma hızının sistemin mikro yapısı üzerinde büyük etkilerinin olduğunun işaretidir. Her iki süreçte sistemde meydana gelen kristal-sıv1 ve siv1-kristal faz geçişlerini analiz etmek için, MD benzetim yöntemlerinde yaygın olarak tercih edilen $g(r)^{\prime}$ yi kullandik. Vanadyumun yapısının sıcaklığa bağlı değişiminde soğutma oranının etkisini görebilmek adına temsili dört farklı soğutma oran $(\mathrm{Q}=0.05,0.1,1$ ve $10 \mathrm{~K} / \mathrm{ps})$ için farklı sicaklıklarda hesaplanan $g(r)$ eğrileri Şekil 3a-3d'de gösterilmektedir. Tekrardan kaçınmak amacıyla diğer soğutma oranlarına ait sonuçlar burada gösterilmemiştir.

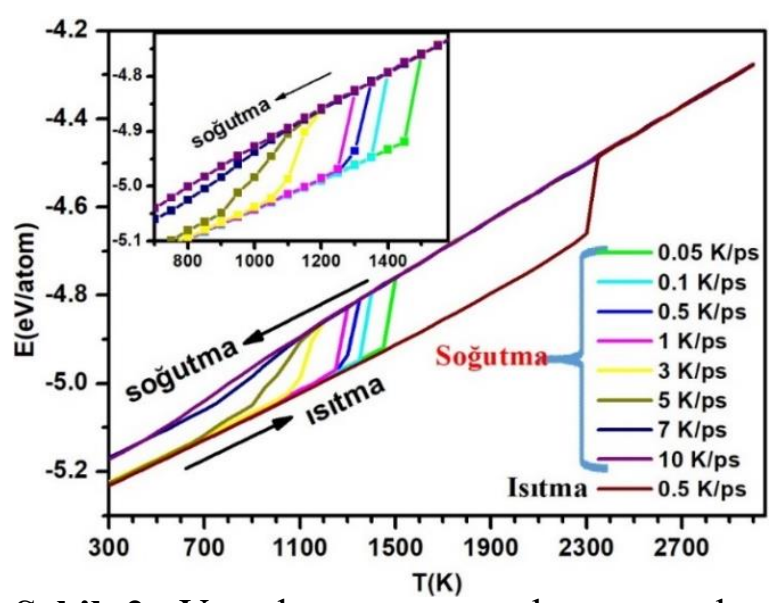

Şekil 2. Vanadyumun atom başına toplam enerjisinin 1sıtma ve soğutma süreçlerinde sıcaklığa bağlı (E-T) değişimi. Gömülü şekil, 1600-700 K arasında yalnız soğutma sürecine ait olan E-T değişimini göstermektedir.

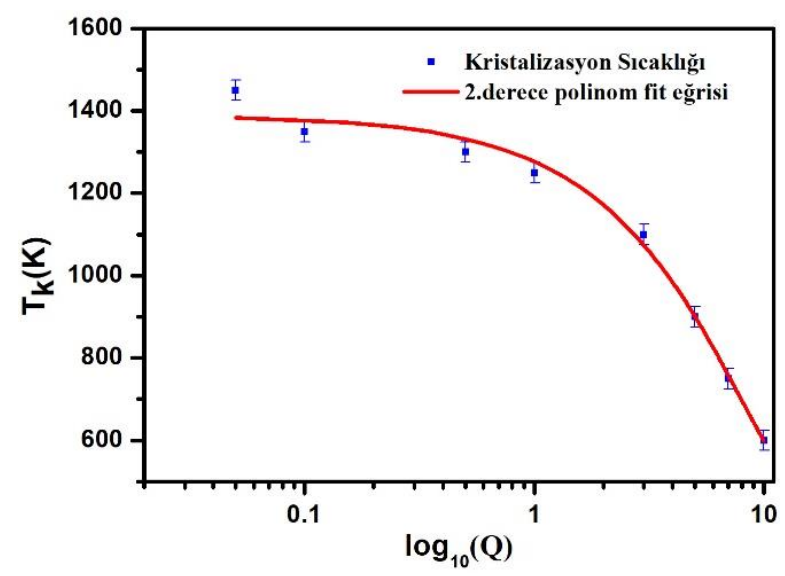

Şekil 3. $T_{k}$ sıcaklığının soğutma oranının logaritmasının fonksiyonu olarak değişimi. 
Her bir soğutma oranı için elde edilen $g(r)$ eğrileri, yüksek sıcaklıklardan $(3000 \mathrm{~K})$ başlayarak kristalizasyon sıcaklığına kadar yumuşak hatlı belirgin iki tepe noktasına sahip olmakla birlikte, bu davranış, sıvı sistemlere ait karakteristik bir özelliktir. Azalan sıcaklık ile birlikte $g(r)^{\prime}$ lerin ilk maksimum pikleri daralmakta ve daha keskin olmaktadır. Buda bize, sıcaklıktaki düşüşe bağlı olarak ilk koordinasyon kabuğundaki atomik düzenin artarak gelişmeye devam ettiğini göstermektedir. Şekil 3(a)'da 1sitma $(0.5$ $\mathrm{K} / \mathrm{ps})$ ve en yavaş soğutma oranı $\left(\mathrm{Q}_{1}=0.05\right.$ $\mathrm{K} / \mathrm{ps}$ ) için farklı sıcaklıklarda hesaplanan $g(r)$ eğrileri karşılaştırılmalı olarak verilmektedir. Yüksek sıcaklıklarda, $3000 \mathrm{~K}$ ve $2600 \mathrm{~K}$ de, 1sıtma ve soğutma eğrilerinin davranışları birbiriyle aynı ve bütün pikler üst üstedir. Sicaklık daha da azaldığında $2150 \mathrm{~K}$ ile 1500 $\mathrm{K}$ arasında, 1sıtma eğrileri kristal yapılara ait keskin ve daha belirgin pikler sergilerken soğutma eğrileri ise sıvılara has pik davranışları sergilemektedir. Sıcaklıktaki düşüşle beraber $1200 \mathrm{~K}$ 'den başlayarak 300 K'e kadar karşılaştırılan ısıtma ve soğutma eğrileri çok küçük farklar dışında neredeyse üst üstedir ve bcc yapılara has kristal pikler sergilemektedir. Mevcut sonuç $\mathrm{Q}_{1}=0.05 \mathrm{~K} / \mathrm{ps}$ soğutma oranı ile soğutulan vanadyum sisteminin sıvı yapıdan bcc kristal yapıya faz geçişi gerçekleştirdiğinin açıkça göstermektedir. Şekil 3(b)-(d)'de verilen $\mathrm{Q}=0.1,1$ ve $10 \mathrm{~K} / \mathrm{ps}$ soğutma oranları için düşük sıcaklıklardaki $g(r)$ eğrileri de $\mathrm{Q}_{1}=0.05$ $\mathrm{K} / \mathrm{ps}$ de olduğu gibi bcc yapıya has pikler vermektedir. Fakat bu pikler soğutma hızına göre küçük farklılıklar göstermekte olup pik yükseklikleri yavaş soğutmadan hızlı soğutmaya doğru azalmaktadır. Diğer yandan Şekil 3(a)-(d)'de dört farklı soğutma oranı için elde edilen $g(r)$ eğrilerinden gözlenen "azalan sıcaklığa bağlı olarak farklı sicaklıklarda sıvıdan bcc kristal yapıya geçiş”, yukarıda tartışılan E- $T$ eğrilerinin (Şekil 2) soğutma oranına bağlı değişimi ile de tutarlıdır. Analiz sonuçlarımız, tercih edilen soğutma oranının sistemin yapısının ve kristalizasyon sürecinin gelişimde önemli etkilerinin olduğunu göstermektedir. Şekil 4'de $\mathrm{Q}_{1}=0.05 \mathrm{~K} / \mathrm{ps}$ oranını için $2150 \mathrm{~K}$ sıcaklıkta hesaplanan $g(r)$ ve $\quad g(r)$ 'nin Fourier dönüşümünden hesaplanan yap1 faktörleri $(S(q))$ Waseda Waseda (1981) tarafindan verilen 2183 K'deki deneysel sonuçlarla birlikte gösterilmiştir. Isıtılan sistem $2300 \pm 25 \mathrm{~K}$ civarında erimiştir. $\mathrm{Bu}$ sıcaklık deneysel erime sıcaklığından $(\sim 2183 \quad \mathrm{~K})$ büyük olduğundan deneysel $S(q)$ ve $g(r)$ 'leri, soğutma sürecinden $\left(\mathrm{Q}_{1}=0.05 \mathrm{~K} / \mathrm{ps}\right)$ elde ettiğimiz eğrilerle karşılaştırdık. Sonuçlarımız deneysel sonuçlar ile ilk piklerin konumundaki çok küçük farkların dışında çoğunlukla uyumludur ve bu MD benzetimin güvenirliği açısından önemli bir sonuçtur.
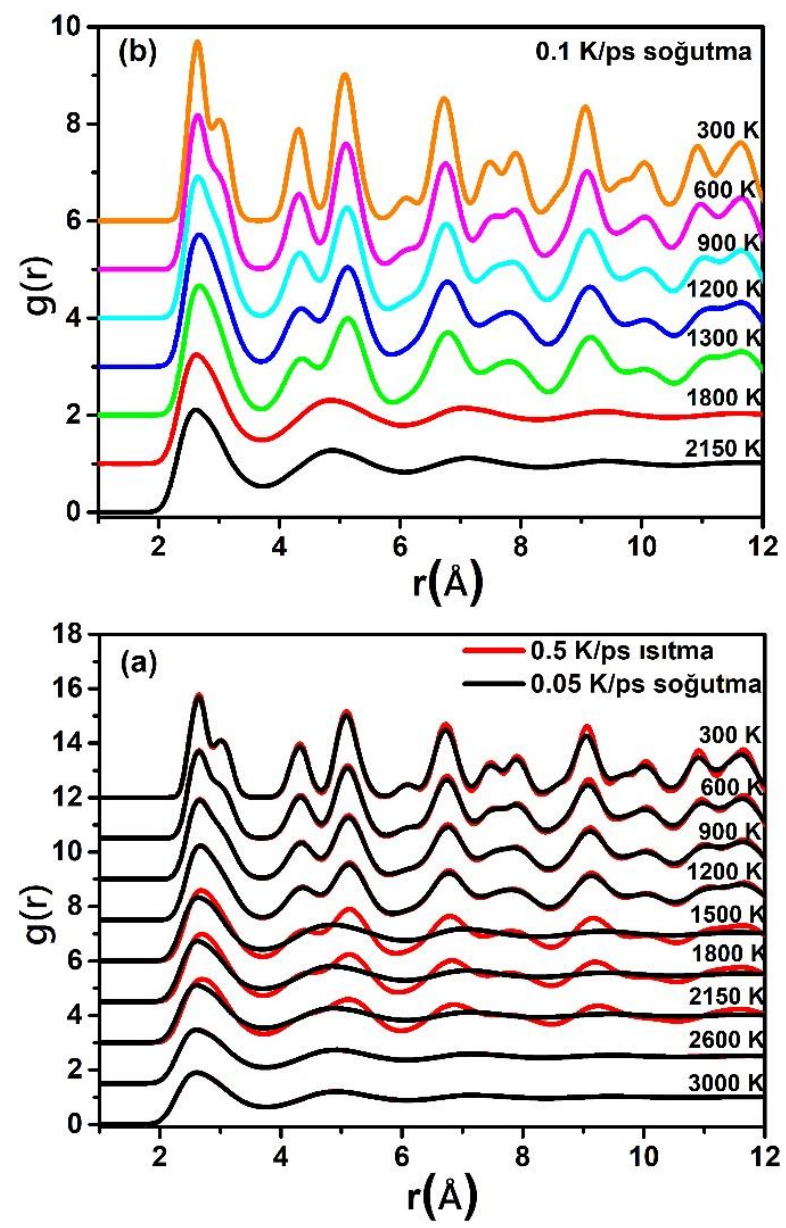

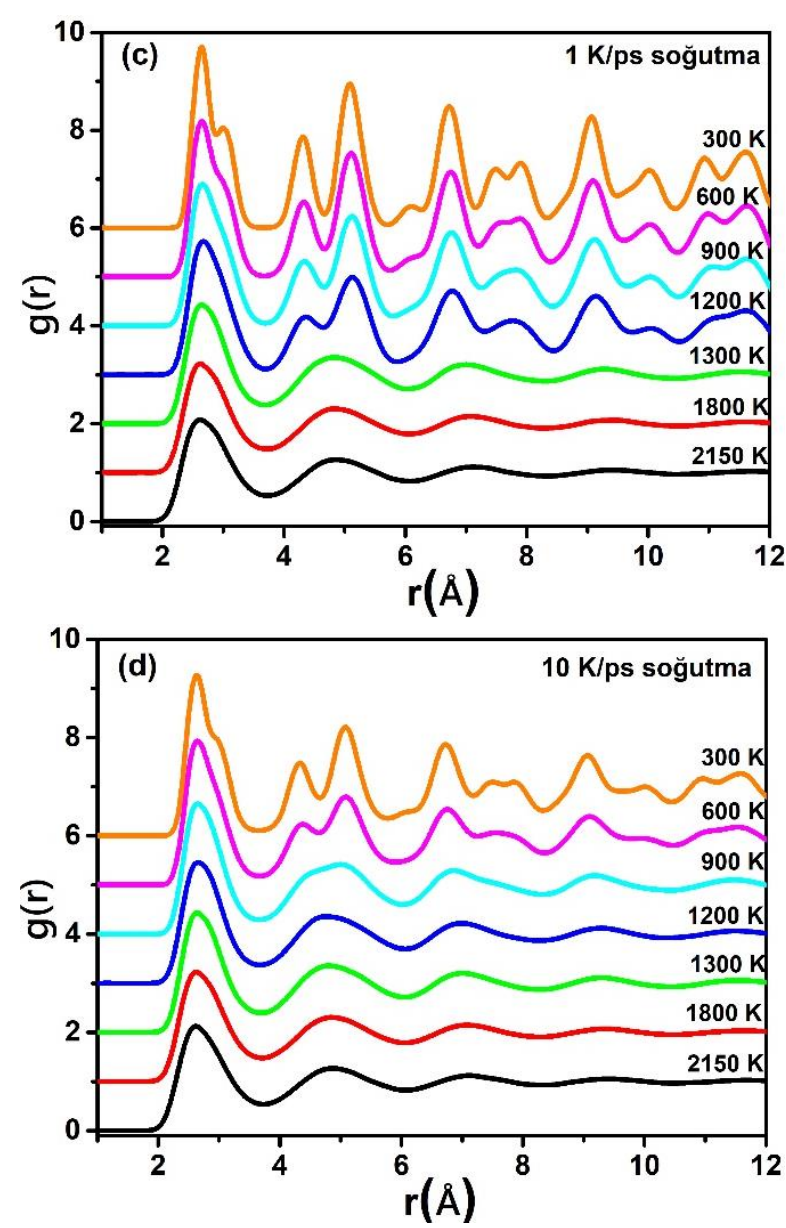

Şekil 3. (a) $\mathrm{Q}_{1}=0.05 \mathrm{~K} / \mathrm{ps}$ (ve 1sıtma), (b) $\mathrm{Q}_{2}=0.1 \mathrm{~K} / \mathrm{ps}$, (c) $\mathrm{Q}_{4}=1 \mathrm{~K} / \mathrm{ps}$ ve (d) $\mathrm{Q}_{8}=10 \mathrm{~K} / \mathrm{ps}$ soğutma oranı için farklı sıcaklıklarda hesaplanan $g(r)$ eğrileri.

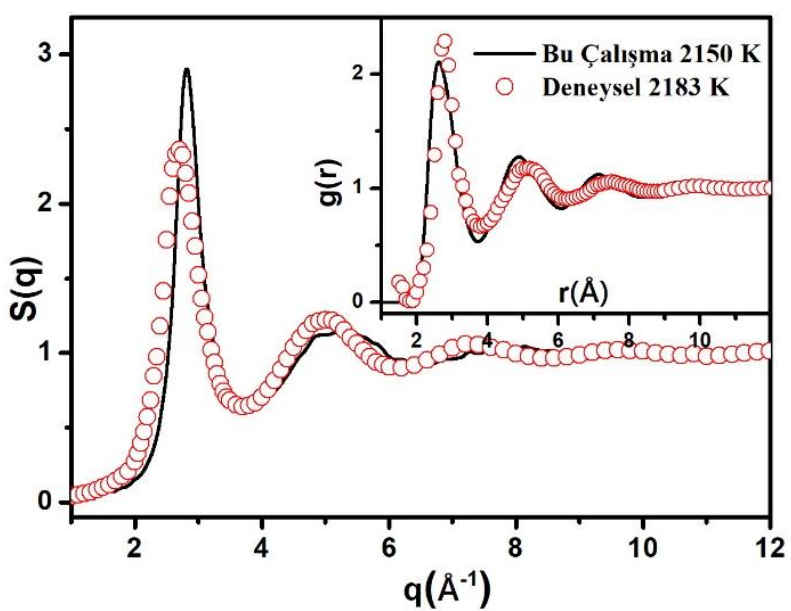

Şekil 4. $\mathrm{Q}_{1}=0.05 \mathrm{~K} / \mathrm{ps}$ soğutma oran1 için hesaplanan ve deneysel $S(q)$ ve $g(r)$ eğrileri (Waseda, 1981).

Her ne kadar $g(r)$, sistemin faz geçişinin genel bir tanımını verse de, sistemdeki atomik kümelerin yapısını ve bu kümelerin sürece bağlı değişimlerini tanımlayamaz. Bu sebeple, sicaklıktaki düşüşe bağlı olarak sistemin mikro yapısındaki gelişmeleri ve kısa menzilli düzeni tanımlamak için HA ve VM analiz yöntemlerini kullandık. MD benzetim kutusunun anlık görüntüleri ve çiftler analizi için OVITO Stukowski (2010) yazılımından yararland1k. $Q_{1}=0.05 \mathrm{~K} / \mathrm{ps}$ oranı ile soğutulan sistemin farklı sıcaklıklardaki (2000, 1500, 1400 ve $300 \mathrm{~K}$ ) MD benzetimlerinden alınan temsili görüntüleri ve kristal (veya diğer) kümelerin dağılımları Şekil 5 'te verilmiştir. Tekrardan kaçınmak için diğer soğutma oranlarının sonuçları burada gösterilmemiştir. $2000 \mathrm{~K}$ ve $1500 \mathrm{~K}$ sicakliklarda sistemin görüntülerinden atomların rastgele bir dağılıma sahip olduğu görülmektedir ve ayrıca analiz sonuçları sistemde fcc, hcp ve bcc gibi kristal kümelerin dağılımının neredeyse $\quad \% \quad 0.0 \quad$ civarında olduğunu göstermektedir. HA analiz sonuçları yukarıdaki analiz sonuçlarını destekler şekilde yüksek sıcaklıklarda sistemin sıv1 yapıda olduğunu söylemektedir. $\quad \mathrm{Q}_{1}=0.05 \mathrm{~K} / \mathrm{ps}$ soğutma oranı için sıcaklık $T_{k}=1450 \mathrm{~K}$ erime noktasının altına düştüğünde, $1400 \mathrm{~K}$ ve 300 $\mathrm{K}$ için diğer kümelerin dağılımı çok hızlı bir şekilde azalırken bcc kümelerin dağılımı \% 0.0 civarından sirasiyla $\sim \% 72$ ve $\sim \% 98$ 'e kadar artmıştır. Mevcut sonuçlar sistemin sıv1-bcc kristal faz geçişi gerçekleştirdiğini ve azalan sıcaklık ile bcc kümelerin gelişerek artmaya devam ettiğini göstermektedir. Diğer soğutma oranları $(\mathrm{Q}=0.1,0.5,1,3$ ve $5 \mathrm{~K} / \mathrm{ps})$ için elde edilen HA analiz sonuçları çok küçük farklılıklar dişında $\mathrm{Q}_{1}=0.05 \mathrm{~K} / \mathrm{ps}$ için elde edilen sonuçlara oldukça benzerdir. En hızlı $\mathrm{Q}=7$ ve $10 \mathrm{~K} / \mathrm{ps}$ soğutma oranları için elde edilen sonuçlar yüksek oranda bcc kristal kümelerin dışında önemli oranda farklı kristal kümelerinde varlığına işaret etmektedir (burada gösterilmedi) ve buda soğutma oranının sistemin mikro yapısal 
değişimlerinde belirleyiciliğe sahip olduğunu göstermektedir. Bütün soğutma oranları arasındaki benzerlik ve farklılıkları görebilmek adına bcc yapıyı temsil eden 1441 ve 1661 bağlı çiftlerinin temsili farklı sicakliklarda $(300,600,900$ ve $1100 \mathrm{~K})$ dağılımları sırasıyla Şekil 6(a) ve (b)'de gösterilmiştir. Her iki bağlı çiftin (1441 ve 1661) sicaklığa ve soğutma oranına bağlı değişim eğilimleri birbirine oldukça benzerdir. $\mathrm{Q}=0.05,0.1,0.5,1$ ve $3 \mathrm{~K} / \mathrm{ps}$ soğutma oranları ile soğutulan sistemin HA analiz sonuçları bütün sıcaklıklar için çok küçük farklılıklar dişında birbirine oldukça yakındır. En yavaş beş soğutma oranı için 300 $\mathrm{K}$ deki 1441 ile 1661 bağlı çiftlerinin toplamı $\mathrm{Q}_{1}=0.05 \mathrm{~K} / \mathrm{ps}$ için \% 99.5 ile $\mathrm{Q}_{5}=3 \mathrm{~K} / \mathrm{ps}$ için \% 99.2 dar aralığında değişmektedir. Mevcut sonuçlar bu soğutma oranları ile soğutulan vanadyumun sıvı yapıdan başlangıçtaki kararlı yapısı olan ideal bcc kristal yapıya geçiş yaptığını göstermektedir. Bunun en önemli göstergelerinden biri de başlangıç olarak bcc yapida kurulan ve isitilan sistemin 1441/1661 bağlı çiftlerinin HA sonuçları ile bu soğutma oranlarının HA sonuçlarının aynı olmasıdır. Diğer yandan sistem $\mathrm{Q}=5,7$ ve 10 $\mathrm{K} / \mathrm{ps}$ soğutma oranlarında daha hızlı soğutulduğunda ilk beş yavaş soğutma oranı için elde edilen HA sonuçlarından daha farklı sonuçlar elde edilmiştir. Soğutma oranı arttıça 1441 ve 1661 bağlı çiftlerinin oranının azaldığı gözlenmiştir. Azalan sıcaklıkla birlikte özellikle $600 \mathrm{~K}$ civarından başlayarak 1441 ve 1661 kümelerinin dağglımında önemli bir artış olmuş ve $\mathrm{Q}_{6}=5$ $\mathrm{K} / \mathrm{ps}$ için diğer beş soğutma oranları için elde edilen değerlere ulaşılmıştır. $300 \mathrm{~K}$ de 1441 ile 1661 bağlı çiftlerinin toplamı $\mathrm{Q}_{7}=7 \mathrm{~K} / \mathrm{ps}$ için \% 83.3 ile $\mathrm{Q}_{8}=10 \mathrm{~K} / \mathrm{ps}$ için \% 82.3 olarak hesaplanmıştır. $\mathrm{Bu}$ veriler $\mathrm{Q}_{7}=7 \mathrm{~K} / \mathrm{ps}$ ve $\mathrm{Q}_{8}=10 \mathrm{~K} / \mathrm{ps}$ soğutma oranı için bcc kristal yap1ları temsil eden 1441 ve 1661 bağl1 çiftlerin dışında farklı kümelerinde varlığına işaret etmektedir. MD benzetim sonuçlarına dayalı HA analizi, soğutma oranının vanadyumun soğutulması esnasında oluşan kristalizasyonu ve mikro yapısının gelişimini önemli düzeyde etkilediği sonucunu destekler. Soğutma sürecinde, enerji çekilmesi için sisteme tanınan süre uzadığında sistemdeki kristal çekirdeklenme o kadar yüksek sıcaklıklarda başlar ve gelişir. Sistemin dengeye gelebilmesi için yeteri kadar süre tanınmadığında kristalizasyon sıcaklığı daha düşük sıcaklıklara doğru kayar ve hatta sistemin soğuması için daha da kısa süre tanındığında artık kristal çekirdeklenme ve dolayısı ile kristalizasyon gerçekleşemeden daha düzensiz bir yapı olan amorf yapıya geçiş gerçekleşebilir. Sıvı-amorf geçişi ile ilgili sonuçlar çalışmamızda tartışılmamış olmasına rağmen soğutma oranının etkisini görebilmek adına sistem daha hızlı soğutma oranları $(\mathrm{Q}=20,30,40,50$ ve $100 \mathrm{~K} / \mathrm{ps})$ ile de soğutulmuştur. Elde edilen analiz sonuçları 20 $\mathrm{K} / \mathrm{ps}$ soğutma oranından itibaren sistemin sıvı yapıdan amorf yapıya geçiş yaptığını göstermiştir. Atomik yerel çevrenin gelişimi ve kristalizasyon sürecinde sistemin mikro yapısında neler olup bittiği hakkında daha ayrıntılı bilgiler alabilmek için HA analiz yöntemine göre daha ayrıntılı ve kümelerin üç boyutlu yaklaşımını sunan VM analiz yöntemini kullandık. $\mathrm{Bu}$ yöntem, HA yöntemine göre merkezi bir atomun çevresindeki komşu atomların oluşturduğu geometrik yapıyı daha eksiksiz görmemize olanak sağlar. Ele aldığımız sistemde yüksek sıcaklıklarda pek çok VP kümesi gözlemledik fakat çalışmamızda \%1 ve üzerinde dağılıma sahip olan yaygın VP tiplerini gösterdik ve tartıştık. $\quad Q_{1}=0.05 \quad \mathrm{~K} / \mathrm{ps}$ için yüksek sicaklıklardan başlayarak kristalizasyon sıcaklığına kadar olan geniş aralıkta seçilen sicakliklarda (3000, 2600, 2200, 1800 ve 1500 K) öne çıkan VP'ler Şekil 7(a) gösterilmiştir. 

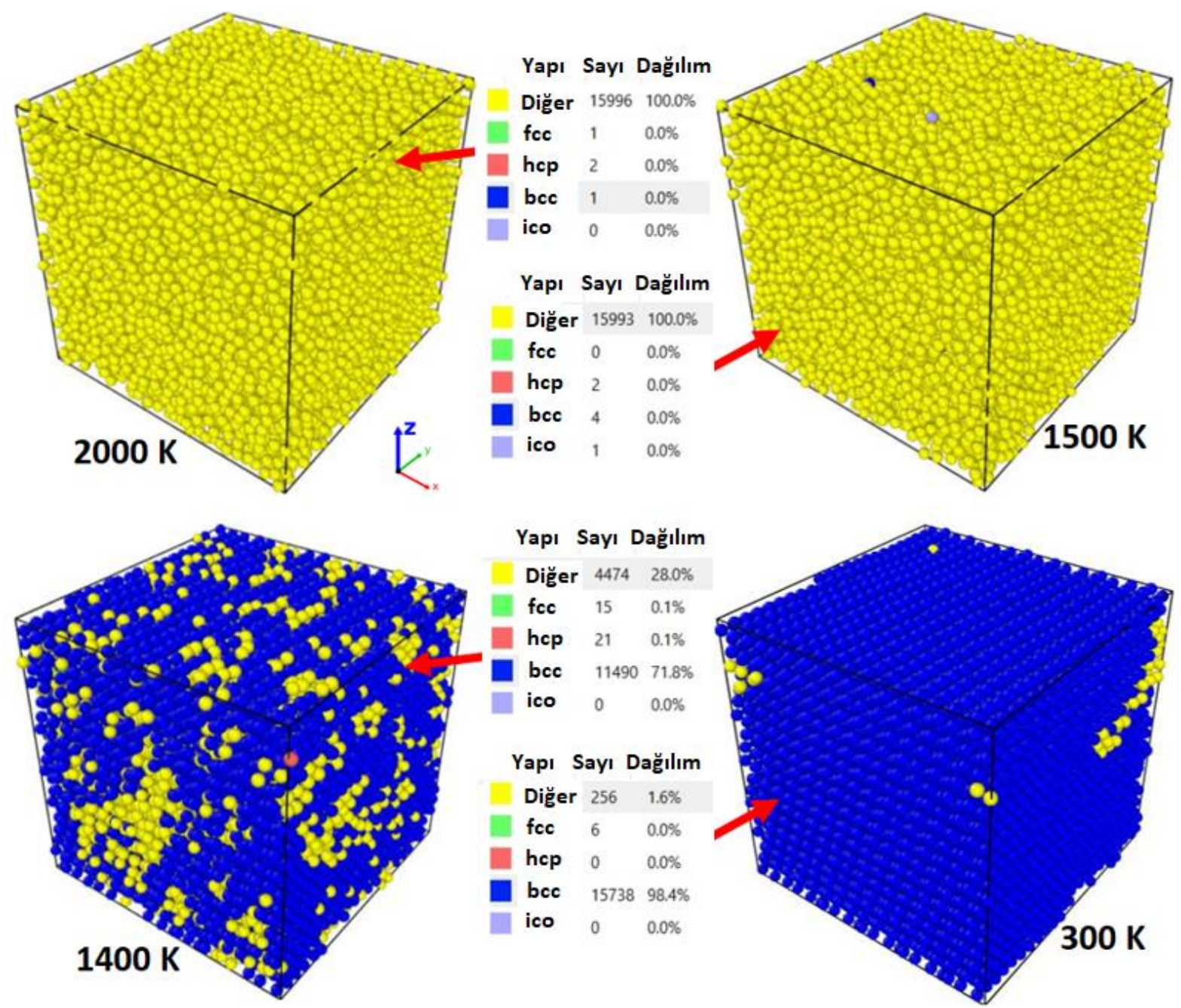

Şekil 5. $\mathrm{Q}_{1}=0.05 \mathrm{~K} / \mathrm{ps}$ soğutma oranı için $2000,1500,1400$ ve $300 \mathrm{~K}$ 'de elde edilen HA analiz sonuçları ve MD benzetim kutularının anlık görüntüleri.
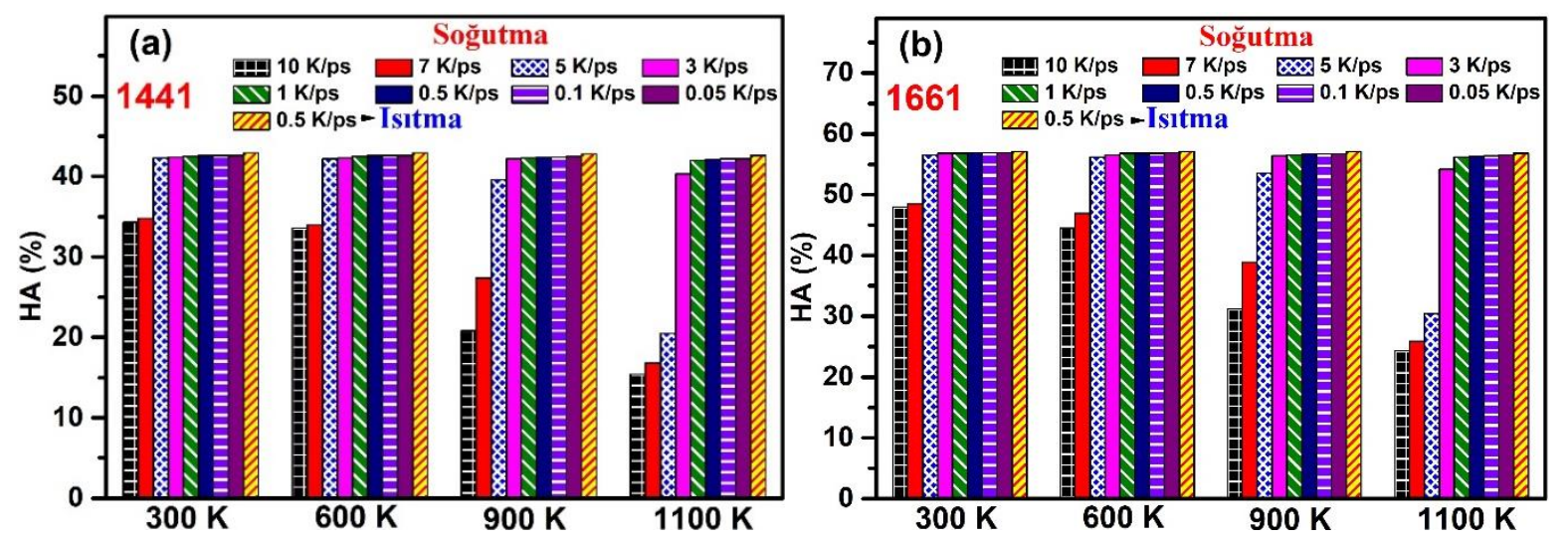

Şekil 6. Farklı sıcaklıklarda $0.5 \mathrm{~K} / \mathrm{ps}$ ısıtma ve sekiz farklı soğutma oranı için (a) 1441 ve (b) 1661 HA endeksleri. 
Bütün sıcaklıklarda en yüksek dağılıma sahip olan Frank-Kasper (FK) çok yüzlülerinden ilk beş tanesi surasıyla $<0,3,6,4>(Z 13),<0,2,8,4>$ (Z14), <0,3,6,5> (Z14), <0,1,10,2> (Z13) ve $<0,4,4,6>$ (Z14) Voronoi endeksleridir. Diğer soğutma oranları için de çok küçük farklılıklar dışında benzer bir dağılım gözlenmiştir. Özellikle azalan sıcakla birlikte Z13 ve Z14 gibi yüksek koordinasyon sayısına sahip VP'lerin dağglımı daha belirgin bir şekilde artmaktadır. Düşük koordinasyon sayılı VP'lerde bu artış daha düşüktür ve bunların içinde yalnızca $<0,3,6,3>$ (Z12) VP'lerinin dağılımı azalmaktadır. Bu soğutma oranı için $1450 \mathrm{~K}$ sıcaklıkta, bcc kümelerini temsil eden Voronoi endeksi $<0,6,0,8>$ kümelerinin (Şekil 7(b) 'de gösterilmiştir) dağılımı, önemli ölçüde artar ve \% 85.12'ye ulaşırken, diğer VP türlerinin dağılımı çok hızlı ve keskin bir şekilde azalmaktadır. Bu ani değişim, aşırı soğutulmuş sıvı vanadyumun bcc benzeri yapıya kristalleştiğini gösterir. Daha önceki yıllarda Pan ve arkadaşları Pan vd. (2015) bcc yapısının, atomik hareket açısından diğer kristallere göre sıvıya daha benzer olduğunu rapor etmişlerdir. Diğer yandan Alexander ve McTague (1978) hızlı soğutma işlemi sırasında çekirdeklenen ilk fazın bcc kristal faz olabileceğini öne sürmüşlerdir. Şekil 7(b)'de 1sıtma ve bütün soğutma oranları için VM analizden elde edilen ideal bcc yapıyı temsil eden $<0,6,0,8>$ VP'lerinin sicaklığa bağlı değişimi gösterilmiştir. $\mathrm{Q}=0.05,0.1,0.5$ ve $1 \mathrm{~K} /$ ps soğutma oranları için $<0,6,0,8>$ kümelerinin dağılımında çok ani keskin bir sıçrama gözlenirken, bu keskin sıçrama $\mathrm{Q}_{5}=3$ $\mathrm{K} / \mathrm{ps}$ soğutma oranından başlayarak daha da belirgin bir şekilde yumuşamaktadır. Düşük sıcaklıklara doğru tüm soğutma oranları arasında en belirgin fark $\mathrm{Q}_{7}=7 \mathrm{~K} / \mathrm{ps}$ ve $\mathrm{Q}_{8}=10$ $\mathrm{K} /$ ps soğutma oranlarında gözlenmiştir. Diğer soğutma oranlarının VP dağılımları, ısıtma sürecinde düşük sıcaklıklarda elde edilen VP dağılımları ile birbirine çok yakındır fakat bu iki soğutma oranı için $<0,6,0,8>$ kümelerinin $300 \mathrm{~K}$ de dağılımı $\% 55$ civarındadır.
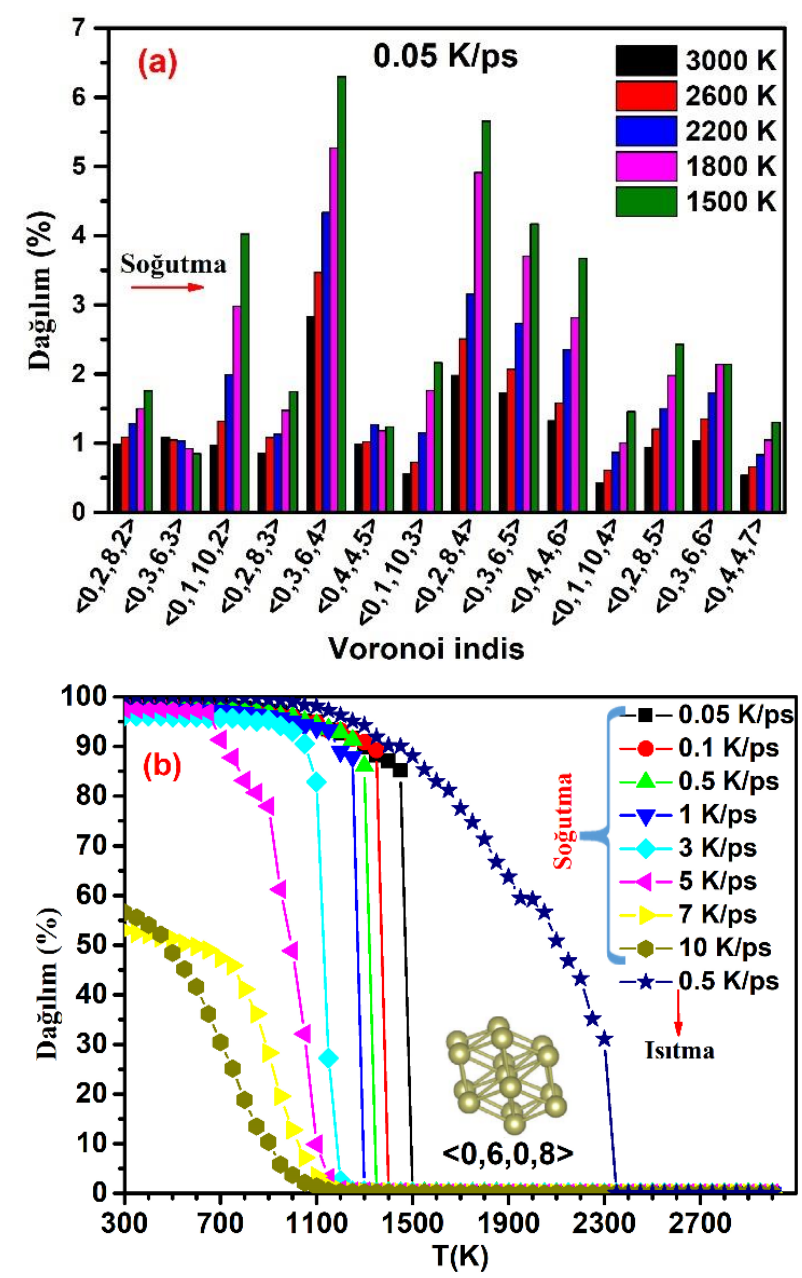

Şekil 7. (a) $\mathrm{Q}_{1}=0.05 \mathrm{~K} / \mathrm{ps}$ soğutma oranı için temsili sıcaklıklardaki yaygın VP'lerin dağılımı. (b) Isıtma ve farklı soğutma oranları için $<0,6,0,8>$ VP'lerin sicaklığa bağl1 dağılımı.

Mevcut sonuçlar ilk altı soğutma oranı için sistemin düşük sıcaklıklarda ideal bcc yapıya geçiş yaptığını gösterirken, son iki soğutma oranı için içinde yüksek oranda farklı kristal yapıları da barındıran bcc-benzeri bir kristal yapıya geçiş yaptığını göstermektedir. Aynı zamanda $<0,6,0,8>$ kümelerinin sicaklığa bağlı davranışının yukarıda tartışılan 1441 ve 1661 bağlı çiftlerine benzer olması HA ve VM analiz yöntemleri arasındaki tutarlılığ1 göstermektedir. 


\section{Sonuç ve Tartışma}

Mevcut çalışmada, vanadyumun 1sitma ve soğutma sürecinde atomik yapısında meydana gelen değişimler GAM potansiyeli kullanılarak MD benzetimiyle araştırıldı. Hızlı soğutma sürecinde vanadyumun kristalizasyon sürecine soğutma oranının ne tür etkisinin olduğunu araştırabilmek için sekiz farkl1 $\left(\mathrm{Q}_{1}=0.05, \mathrm{Q}_{2}=0.1, \mathrm{Q}_{3}=0.5, \mathrm{Q}_{4}=1\right.$, $\mathrm{Q}_{5}=3, \mathrm{Q}_{6}=5, \mathrm{Q}_{7}=7$ ve $\mathrm{Q}_{8}=10 \mathrm{~K} / \mathrm{ps}$ ) soğutma oranı kullanıldı. Başlangıç olarak bec kristal yapıda kurulan sistem için düşük sıcaklıklarda elde edilen bazı fiziksel özellikler literatürdeki ilgili deneysel sonuçlar ile tutarlıdır ve 1sitılan sistem deneysel erime noktasından (2183 K) küçük sapma (\% 4.21 6.5) ile $\mathrm{T}_{\mathrm{e}}=2300 \pm 25 \mathrm{~K}$ de erimiştir. Soğutma oranının sıv1-kristal faz geçişinde büyük etkisinin olduğu gözlenmiştir. Daha yavaş soğutulan sistem daha yüksek sicaklıklarda kristal yapıya geçiş yaparken daha hızlı soğutulan sistem ise daha düşük sicaklıklara doğru sıv1-kristalimsi bir geçiş gerçekleştirmiştir. Soğutma sürecinde elde edilen $g(r)$ ve $S(q)$ eğrileri erime noktası civarındaki deneysel sonuçlarla büyük oranda uyumlu çıkmıştır. Bütün soğutma oranlarının sıv1-kristal faz geçişi neticesinde elde edilen $g(r)$ eğrilerinin pik davranışları ideal bcc kristal yapıların pik davranışları ile tutarlıdır. Düşük sıcaklıklarda $\mathrm{Q}_{7}=7$ ve $\mathrm{Q}_{8}=10 \mathrm{~K} / \mathrm{ps}$ için hesaplanan $g(r)$ 'ler dışında diğer bütün soğutma oranlarının $g(r)$ pik yükseklik ve konumları 1sitma sürecindeki bcc kristal $g(r)$ ile neredeyse üst üste çıkmıştır. HA analiz sonuçları sistemin yavaş soğutma oranları için sıvı-kristal geçişinde bcc kristal yapıyı temsil eden 1441 ve 1661 bağlı çiftlerinin dağılımında çok ani ve keskin bir artışın olduğunu göstermiştir. Soğutma hızı arttıkça bu ani geçişler daha yumuşak hal almıştır. VM analiz sonuçlarına göre her soğutma oranı için kristalizasyon sıcaklığının üzerindeki sicaklıklarda yüksek koordinasyonlu $\langle 0,3,6,4\rangle(\mathrm{Z} 13),\langle 0,1,10,2\rangle(\mathrm{Z} 13),\langle 0,2,8,4\rangle$ (Z14), $\langle 0,3,6,5\rangle$ (Z14) ve $\langle 0,4,4,6\rangle$ (Z14) FK çok yüzlülerinin dağılımı daha baskındır. Sistem kristal olduğunda ideal bcc yapıyı temsil eden $<0,6,0,8>$ kümelerinde 1441 ve 1661 bağlı çiftlerde olduğu gibi ani ve kuvvetli bir artış gözlenmiştir. Yapılan analizler, $\mathrm{Q}_{7}=7 \mathrm{~K} / \mathrm{ps}$ ve $\mathrm{Q}_{8}=10 \mathrm{~K} / \mathrm{ps}$ soğutma oranları hariç sistemin başlangıçta en kararlı yapısı olan ideal bcc kristal yapıya geçiş yaptığını desteklemektedir. En hızlı soğutma oranlarında ise $<0,6,0,8>$ kümelerin dışında farklı kristal kümelerinde var olması bcckristalimsi bir yapının oluştuğunu göstermiştir.

\section{Teşekkür:}

Araştırma boyunca fikirlerini ve yardımlarını bizden esirgemeyen Dr. Sedat ŞENGÜL ve Dr. Ünal DÖMEKELİ'ye teşekkür ederiz. Çalışma ortamını ve gerekli donanımları sağlayan T.Ü. Eğitim Fakültesi yönetimine teşekkür ederiz.

\section{Kaynaklar}

Alder, B. J., Wainwright, T. E. 1957. "Phase Transition for a Hard Sphere System", The Journal of Chemical Physics, 27(5), 12081209.

Alexander, S., McTague, J. 1978. "Should All Crystals Be bcc? Landau Theory of Solidification and Crystal Nucleation", Physical Review Letters, 41(10), 702-705.

Ashkenazy, Y., Averback, R. S. 2010. "Kinetic stages in the crystallization of deeply undercooled body-centered-cubic and facecentered-cubic metals", Acta Materialia, 58(2), 524-530.

Bolef, D. I., Smith, R. E., Miller, J. G. 1971. "Elastic Properties of Vanadium. I. Temperature Dependence of the Elastic Constants and the Thermal Expansion", 
Physical Review B, 3(12), 4100-4108.

Celik, F. A. 2012. "Molecular dynamics simulation of crystallization of amorphous aluminium modelled with EAM", Bitlis Eren University Journal of Science and Technology, 2, 44-48.

Celtek, M., Sengul, S. 2018a. "The characterisation of atomic structure and glassforming ability of the $\mathrm{Zr}-\mathrm{Cu}-\mathrm{Co}$ metallic glasses studied by molecular dynamics simulations", Philosophical Magazine, 98(9), 783-802.

Celtek, M., Sengul, S. 2018b. "Thermodynamic and dynamical properties and structural evolution of binary $\mathrm{Zr} 80 \mathrm{Pt} 20$ metallic liquids and glasses: Molecular dynamics simulations", Journal of NonCrystalline Solids, 498, 32-41.

Çeltek, M., Şengül, S. 2019. "Effects of cooling rate on the atomic structure and glass formation process of Co90Zr10 metallic glass investigated by molecular dynamics simulations", Turkish Journal of Physics, 43(1), 11-25.

Celtek, M., Sengul, S., Domekeli, U. 2017. "Glass formation and structural properties of Zr50Cu50-xAlx bulk metallic glasses investigated by molecular dynamics simulations", Intermetallics, 84, 62-73.

Çeltek, M., Şengül, S., Dömekeli, Ü. 2019. "Hizlı Soğutma Sürecinde Dörtlü Zr48Cu36Ag8A18 İri Hacimli Metalik Camının Atomik Yapısının Gelişimi", Süleyman Demirel Üniversitesi Fen Bilimleri Enstitüsü Dergisi, 23(3), 954-962.

Celtek, M. 2019. "The effect of atomic concentration on the structural evolution of Zr100-xCox alloys during rapid solidification process", Journal of Non-Crystalline Solids, 513, 84-96.

Chung, H. M., Loomis, B. A., Smith, D. L. 1996. "Development and testing of vanadium alloys for fusion applications", Journal of
Nuclear Materials, 239, 139-156.

Daw, M. S., Baskes, M. I. 1984. "Embedded atom method: derivation and application to impurities,surfaces and other defects in metal", Phsical Review B, 29(12), 6443-6453.

Debela, T. T., Wang, X. D., Cao, Q. P., Zhang, D. X., Jiang, J. Z. 2014. "The crystallization process of liquid vanadium studied by $a b$ initio molecular dynamics", Journal of Physics: Condensed Matter, 26(15), 155101.

Debela, T. T., Wang, X. D., Cao, Q. P., Zhang, D. X., Wang, S. Y., Wang, C. Z., Jiang, J. Z. 2014. "Atomic structure evolution during solidification of liquid niobium from ab initio molecular dynamics simulations", Journal of Physics Condensed Matter, 26(5), 055004

Egry, I., Holland-Moritz, D. 2011. "Levitation methods for structural and dynamical studies of liquids at high temperatures", European Physical Journal: Special Topics.

Ganesh, P., Widom, M. 2006. "Signature of nearly icosahedral structures in liquid and supercooled liquid copper", Physical Review B, 74(13), 134205.

Greiner, J. D., Carlson, O. N., Smith, J. F. 1979. "Single-crystal elastic constants of vanadium and vanadium with oxygen additions", Journal of Applied Physics, 50(6), 4394-4398.

Haynes, W. M. 2015. "CRC Handbook of Chemistry and Physics 95th Edition", CRC Press LLC, Boca Raton.

Honeycutt, J. D., Andersen, H. C. 1987. "Molecular Dynamics Study of Melting and Freezing of Small Lennard- Jones Clusters", Journal of Physical Chemistry, 91(24), 49504963.

Hoyt, J. J., Asta, M., Sun, D. Y. 2006. "Molecular dynamics simulations of the crystal-melt interfacial free energy and mobility in Mo and V", Philosophical Magazine, 86(24), 3651-3664. 
Itami, T., Munejiri, S., Masaki, T., Aoki, H., Ishii, Y., Kamiyama, T., Hoshino, K. 2003. "Structure of liquid $\mathrm{Sn}$ over a wide temperature range from neutron scattering experiments and first-principles molecular dynamics simulation: A comparison to liquid Pb", Physical Review B, 67(6), 064201.

Jakse, N., Pasturel, A. 2003. "Local Order of Liquid and Supercooled Zirconium by $\mathrm{Ab}$ Initio Molecular Dynamics", Physical Review Letters, 91(19), 195501.

Jakse, N., Pasturel, A. 2004. "Ab initio molecular dynamics simulations of local structure of supercooled Ni", The Journal of Chemical Physics, 120(13), 6124-6127.

Kelton, K. F., Lee, G. W., Gangopadhyay, A. K., Hyers, R. W., Rathz, T. J., Rogers, J. R., Robinson, D. S. 2003. "First X-Ray Scattering Studies on Electrostatically Levitated Metallic Liquids: Demonstrated Influence of Local Icosahedral Order on the Nucleation Barrier", Physical Review Letters, 90(19), 195504.

Kim, T. H., Lee, G. W., Sieve, B., Gangopadhyay, A. K., Hyers, R. W., Rathz, T. J., Goldman, A. I. 2005. "In situ High-Energy X-Ray Diffraction Study of the Local Structure of Supercooled Liquid Si", Physical Review Letters, 95(8), 085501.

Kittel, C. 1986. "Introduction to Solid State Physics", John Wiley Sons Inc, New York.

Lou, H., Wang, X., Cao, Q., Zhang, D., Zhang, J., Hu, T., Jiang, J.-Z. 2013. "Negative expansions of interatomic distances in metallic melts", Proceedings of the National Academy of Sciences, 110(25), 10068-10072.

Mandell, M. J., McTague, J. P., Rahman, A. 1977. "Crystal nucleation in a threedimensional Lennard-Jones system. II. Nucleation kinetics for 256 and 500 particles", The Journal of Chemical Physics, 66(7), 3070-3075.

Mauro, N. A., Bendert, J. C., Vogt, A. J., Gewin, J. M., Kelton, K. F. 2011. "High energy x-ray scattering studies of the local order in liquid Al", The Journal of Chemical Physics, 135(4), 044502.

Morishita, K., Diaz De La Rubia, T. 1995. "A Molecular Dynamics Simulation Study of Defect Production in Vanadium", MRS Proceedings, 396, 39.

Olsson, P. A. T. 2009. "Semi-empirical atomistic study of point defect properties in BCC transition metals", Computational Materials Science, 47(1), 135-145.

Ori, G., Montorsi, M., Pedone, A., Siligardi, C. 2011. "Insight into the structure of vanadium containing glasses: A molecular dynamics study", Journal of Non-Crystalline Solids, 357(14), 2571-2579.

Pan, S.-P., Feng, S.-D., Qiao, J.-W., Wang, W.-M., Qin, J.-Y. 2015. "Crystallization pathways of liquid-bcc transition for a model iron by fast quenching", Scientific Reports, 5(1), 16956.

Plimpton, S. 1995. "Fast Parallel Algorithms for Short-Range Molecular Dynamics", Journal of Computational Physics, 117(1), 119.

Schenk, T., Holland-Moritz, D., Simonet, V., Bellissent, R., Herlach, D. M. 2002. "Icosahedral Short-Range Order in Deeply Undercooled Metallic Melts", Physical Review Letters, 89(7), 075507.

Schöpe, H. J., Bryant, G., van Megen, W. 2006. "Two-Step Crystallization Kinetics in Colloidal Hard-Sphere Systems", Physical Review Letters, 96(17), 175701.

Schuh, C., Hufnagel, T., Ramamurty, U. 2007. "Mechanical behavior of amorphous alloys", Acta Materialia, 55(12), 4067-4109.

Sengul, S. 2020. "Evolution of local structure during melting of $\mathrm{Zr} 0.7 \mathrm{Pd} 0.3$ nanowires by molecular dynamics simulations", Vacuum, 174, 109197.

Sengul, S., Celtek, M., Domekeli, U. 2020. 
"The structural evolution and abnormal bonding ways of the $\mathrm{Zr} 80 \mathrm{Pt} 20$ metallic liquid during rapid solidification under high pressure", Computational Materials Science, 172, 109327.

Sengul, S, Celtek, M. 2018. "Pressure Effects on the Structural Evolution of Monatomic Metallic Liquid Hafnium", BEU Journal of Science, 7(1), 144-158.

Shuleshova, O., Löser, W., Holland-Moritz, D., Herlach, D. M., Eckert, J. 2012. "Solidification and melting of high temperature materials: In situ observations by synchrotron radiation", Journal of Materials Science, 47, 4497-4513.

Silvestrelli, P. L., Ambrosetti, A. 2019. "Liquid-glass transition in monoatomic vanadium: A first-principles study", Physical Review B, 99(9), 094201.

Sorkin, V., Polturak, E., Adler, J. 2003a. "Molecular dynamics study of melting of the bcc metal vanadium. I. Mechanical melting", Physical Review B - Condensed Matter and Materials Physics, 68, 174102.

Sorkin, V., Polturak, E., Adler, J. 2003 b. "Molecular dynamics study of melting of the bcc metal vanadium. II. Thermodynamic melting", Physical Review B, 68(17), 174103.

Stukowski, A. 2010. "Visualization and analysis of atomistic simulation data with OVITO-the Open Visualization Tool", Modelling and Simulation in Materials Science and Engineering, 18(1), 015012.

Thakor, P. B., Sonvane, Y. A., Jani, A. R. 2011. "Structural properties of some liquid transition metals", Physics and Chemistry of Liquids, 49(4), 530-549.

Todorov, I. T., Smith, W., Trachenko, K., Dove, M. T. 2006. "DL_POLY_3: new dimensions in molecular dynamics simulations via massive parallelism", Journal of Materials Chemistry, 16(20), 1911.
Voronoi, G. 1908. "New Parametric Applications Concerning the Theory of Quadratic Forms - Second Announcement", $J$. Reine Angew. Math., 134, 198-287.

Waseda, Y. 1981. "The Structure of NonCrystalline Materials-Liquids and Amorphous Solids", London: McGraw-Hill, New York.

Wu, S., Fang, X. W., Wang, S. Y., Wang, C. Z., Yao, Y. X., Ho, K. M., Chen, L. Y. 2011. "Fluctuation between icosahedral and bodycentered-cube short-range orders in undercooled $\mathrm{Zr}$ liquid", Journal of Applied Physics, 110(10), 103518.

Zhang, L., Huang, H. 2006. "Young's moduli of $\mathrm{ZnO}$ nanoplates: Ab initio determinations", Applied Physics Letters, 89, 183111.

Zinkle, S., Matsui, H., Smith, D., Rowcliffe, A., Van Osch, E., Abe, K., Kazakov, V. 1998. "Research and development on vanadium alloys for fusion applications", Journal of Nuclear Materials, 258-263, 205-214. 